\title{
Clinical outcomes of treatment with locking compression plates for distal femoral fractures in a retrospective cohort
}

Masahiro Kiyono ${ }^{1}$ (D), Tomoyuki Noda ${ }^{2 *}$, Hiroshi Nagano ${ }^{3}$, Takashi Maehara ${ }^{4}$, Yasuaki Yamakawa ${ }^{5}$, Yusuke Mochizuki', Takahiko Uchino', Suguru Yokoo', Koji Demiya', Kenta Saiga', Yasunori Shimamura ${ }^{1}$ and Toshifumi Ozaki ${ }^{1}$

\begin{abstract}
Background: Plate fixation is one of the standard surgical treatments for distal femoral fractures. There are few reports on the relationship between the screw position and bone union when fixing by the bridging plate (relative stability) method.

Methods: This retrospective study included 71 distal femoral fractures of 70 patients who were treated with the locking compression plate for distal femur (DePuy Synthes Co., Ltd, New Brunswick, CA, USA). The following measurements were evaluated and analyzed: (1) bone union rate, (2) bridge span length (distance between screws across the fracture), (3) plate span ratio (plate length/bone fracture length), (4) number of empty holes (number of screw holes not inserted around the fracture), and (5) medial fracture distance (bone fracture distance on the medial side of the distal femur). Patient demographics (age), comorbidities (smoking, diabetes, chronic steroid use, dialysis), and injury characteristics (AO type, open fracture, infection) were obtained for all participants. Univariate analysis was performed on them.
\end{abstract}

Results: Of 71 fractures, 26 fractures were simple fractures, 45 fractures were comminuted fractures, and 7 fractures resulted in non-union. Non-union rate was significantly higher in comminuted fractures with bone medial fracture distance exceeding $5 \mathrm{~mm}$.

Non-union was founded in simple fractures with bone medial fracture distance exceeding $2 \mathrm{~mm}$, but not significant $(p=0.06)$. In cases with simple fractures, one non-union case had one empty hole and one non-union case had four empty holes, whereas in cases with comminuted fractures, five non-union cases had two more empty holes.

Conclusions: We concluded that bone fragment distance between fracture fragments is more important than bridge span length of the fracture site and the number of empty holes. Smoking and medial fracture distance are prognostic risk factors of nonunion in distal femoral fractures treated with LCP as bridging plate.

Keywords: Distal femur fracture, Relative stability, Bridging plate, Locking compression plate, Empty hole

\footnotetext{
* Correspondence: tnoda@md.okayama-u.ac.jp

${ }^{2}$ Department of Musculoskeletal Traumatology, Graduate School of Medicine,

Dentistry and Pharmaceutical Sciences, Okayama University, 2-5-1

Shikata-cho, Okayama City, Okayama 700-8558, Japan

Full list of author information is available at the end of the article
}

(c) The Author(s). 2019 Open Access This article is distributed under the terms of the Creative Commons Attribution 4.0 International License (http://creativecommons.org/licenses/by/4.0/), which permits unrestricted use, distribution, and reproduction in any medium, provided you give appropriate credit to the original author(s) and the source, provide a link to the Creative Commons license, and indicate if changes were made. The Creative Commons Public Domain Dedication waiver (http://creativecommons.org/publicdomain/zero/1.0/) applies to the data made available in this article, unless otherwise stated. 


\section{Introduction}

Distal femoral fractures comprise only $0.4 \%$ of all fractures and $4-6 \%$ of femoral fractures $[1,2]$. However, the non-union rate of distal femoral fractures lies between 0 and $34 \%$, indicating considerable variation [3, 4]. Surgical treatment can either be retrograde intramedullary nail fixation or be plate fixation, with plate fixation having a wide indication for various fractures types $[5,6]$.

Regarding plate fixation, basic fixation is generally recommended to achieve absolute stability using lag screws in simple fractures; however, lag screw fixation cannot be performed in transverse fractures [7]. Moreover, it is impossible to achieve absolute stability with rigid internal fixation in comminuted fractures. In such cases, it is necessary to use a locking plate as a bridging plate to fix the fracture site [8]. The optimal insertion holes for the screws on the proximal side of the locking plate (when used as a bridge) are currently debated $[9,10]$. Therefore, in this study, we examined the correlation between bone union and screw position, as the X-ray parameter.

\section{Patients and methods}

This study received Institutional Review Board approval, and patients provided oral and written informed consents. The present study was approved by Okayama University Graduate School of Medicine, Dentistry, and Pharmaceutical Sciences and Okayama University Hospital (Ethics Committee No. 1712-035).

This study included 71 distal femoral fractures in 70 patients (23 males, 47 females; mean age, 68.0 years [range, 16-91 years]) who were treated using the locking

Table 1 Characteristics of distal femoral fractures

\begin{tabular}{ll}
\hline Characteristics & Number of fractures \\
\hline Sex & 23 \\
Male & $47^{*}$ \\
Female & \\
AO/OTA fracture classification & 38 \\
33A & 21 \\
A2 & 17 \\
A3 & 33 \\
33C & 5 \\
C1 & 13 \\
C2 & 15 \\
C3 & \\
Open or closed & 19 \\
Open & 52 \\
Closed & \\
\hline
\end{tabular}

AO/OTA Arbeitsgemeinschaft für Osteosynthesefragen/Orthopedic Trauma Association

*One female had bilateral distal femoral fractures compression plate for distal femur (DePuy Synthes Co., Ltd, New Brunswick, CA, USA) at a university hospital and related facilities between April 2005 and December 2015. One female patient had bilateral femoral fractures. Cases in which the proximal and distal bone fragments were fixed using a lag screw and those in which the medial plate was used during the initial surgery were excluded. All surgery was performed by surgeons with more than 15 years of orthopedic experience at university hospital and related facilities.

The mean follow-up period was 20.8 months (range, 5-33 months) (Table 1). Simple fractures were defined as $33 \mathrm{~A} 2$ and $33 \mathrm{C} 1$ classifications and comminuted fractures were classified as 33A3, 33C2, and 33C 3 according to the Arbeitsgemeinschaft für Osteosynthesefragen/ Orthopedic Trauma Association (AO/OTA) fracture classification [11]; we excluded 33B type AO/OTA fractures. There were 26 simple fractures and 45 comminuted fractures based on plain antero-posterior (AP) and lateral X-ray images (Table 2).

In this study, we investigated (1) bone union rate, (2) bridge span length (distance between screws across the fracture), (3) plate span ratio (plate length/bone fracture length), (4) number of empty holes (number of screw holes not inserted around the fracture), and (5) medial fracture distance (bone fracture distance on the medial side of the distal femur).

Bone union was defined as three out of four instances of cortical bridging on AP and lateral radiographs [12]. Non-union was defined as a state in which bone union was not achieved within 4 months after the initial surgery. Working length of a plate was defined as the distance between the first screws on either side of the fracture [13]. Plate span ratio was measured with reference to the length of the plate relative to the length of the fracture line, as proposed by Gautier et al. and Stoffel et al. [14, 15]. Guidelines for defining the terms "plate span ratio," "empty hole," and "medial fracture distance" are provided in Fig. 1a, b, and c. Measurements of the medial fracture distance between the proximal fragment and the medial cortex of the distal fragment were based on plain AP and lateral X-ray images. For cases in whom the bone fracture site was shortened by surgeon, the medial distance was regarded as $0 \mathrm{~mm}$. When an intermediate bone fragment exceeding $20 \mathrm{~mm}$ was included in the measurement range, the distance between the both ends and the main bone fragment was measured.

Fisher's exact test was performed for statistical comparisons of open fractures, minimally invasive plate osteosynthesis, plate span ratio, and medial fracture distance between those with bone union (bone union group) and those with non-union (non-union group). The Mann-Whitney $U$ test was performed for statistical comparisons of the average number of empty holes and 
Table 2 Characteristics of non-unions compared with fractures that healed

\begin{tabular}{llll}
\hline Characteristics & Non-union $(n=7)$ & Union $(n=64)$ & $p$ value \\
\hline Age, years & $61.5 \pm 18.4$ & $68.4 \pm 18.7$ & 15 \\
Open fracture & 4 & 55 & 0.25 \\
MIPO & 6 & 24 & 0.07 \\
Simple fracture (AO/OTA 33A2/C1) & 2 & 40 & 0.49 \\
Comminuted fracture (AO/OTA 33A3/C2/C3) & 5 & $1.67 \pm 1.89$ & 0.17 \\
Number of empty holes & $2.0 \pm 0.8$ & $85.9 \pm 30.0$ & 0.68 \\
Bridge span length (mm) & $78.3 \pm 29.5$ &
\end{tabular}

Data are presented as mean \pm standard deviation or number. Comparisons were conducted using Fisher's exact test

MIPO minimally invasive plate osteosynthesis, AO/OTA Arbeitsgemeinschaft für Osteosynthesefragen/Orthopedic Trauma Association

the average bridge span length. Results with a $p$ value of $<0.05$ were considered significant.

\section{Results}

In this study, non-union was diagnosed in 7 of 71 cases. Non-union was diagnosed 2 of $26(7.7 \%)$ cases with a simple fracture and 5 of 45 (11.1\%) cases with a comminuted fracture (Table 2). As a salvage surgery for 7 nonunion cases, two patients added a plate on the medial side of the femur (one case also used bone grafting), the other one performed only bone grafting, two cases left an existing plate with replacing the position of the screw, one case replaced with a long plate, and last case was shortened the fracture site and performed bone grafting and plate fixation. Fourteen of all comminuted fracture cases and bone union were treated through shortening the fracture site as Rekha reported [16], and non-union was not observed in these cases. Tables 2, 3, and 4 summarize the univariate analysis. Only smoking and medial fracture distance were statistically significant $(p<$ 0.05 ) independent risk factors predictive of nonunion requiring intervention. Age, open fracture, MIPO, diabetes, steroid use, infection, AO classification, plate span ratio, and bridge span length were of no predictive value.

The mean bridge span length of simple fractures in the bone union and non-union groups was $72.2 \mathrm{~mm}$ (range, $25-110 \mathrm{~mm}$ ) and $72.5 \mathrm{~mm}$ (range, $45-100 \mathrm{~mm}$ ), respectively (Table 3 ). On the other hand, the mean bridge span length of comminuted fractures in the bone union and non-union groups was $92.5 \mathrm{~mm}$ (range, 45$190 \mathrm{~mm}$ ) and $81.2 \mathrm{~mm}$ (range, $40-110 \mathrm{~mm}$ ), respectively (Table 4). No statistically significant difference in the working lengths of the fracture site was observed between simple fractures and comminuted fractures in both groups (Tables 3 and 4).

With respect to plate span ratio, 3 of $24(12.5 \%)$ cases with simple fractures in the bone union group fit the plate length that was $>8-10$ times longer than the overall fracture length, whereas 21 of 24 (87.5\%) cases did not. Additionally, none of the cases in the non-union group fit the plate length of $>8-10$ times longer than the overall fracture length (Table 3). Furthermore, 36 of 40 (90\%) cases with comminuted fractures in the bone union group fit the plate length that was $>2-3$ times longer than the overall fracture length, whereas 4 of 40 (10\%) cases did not. All the cases in the non-union group fit the plate length of $>2-3$ times longer than the overall fracture length (Table 4).

Of the cases with simple fractures, there was one nonunion case with one empty hole and one non-union case with four empty holes (Table 3). Conversely, in cases with comminuted fractures, there were five non-union cases with more two empty holes (Table 4).

Of 26 simple fractures, there were 7 cases with a medial fracture distance of $\geq 2 \mathrm{~mm}$, and the non-union rate was $28.5 \%$ ( 2 of the 7 cases) (Table 3). Additionally, there were 13 comminuted fractures with a medial fracture distance of $\geq 2 \mathrm{~mm}$, and the non-union rate was $30.7 \%$ (4 of the 13 cases). In cases with comminuted fractures, there were five cases with bone fracture distance of $\geq 5 \mathrm{~mm}$ (each length was $5,5,6,8,9 \mathrm{~mm}$ ) on the medial side of the distal femur; all cases resulted in non-union, resulting in a $100 \%$ non-union rate in those with a wide bone distance.

Open fractures were observed in 19 of 71 (26.8\%) cases (Table 1). Of the comminuted fractures, 18 open fractures were observed; four cases resulted in nonunion, which was not a significantly larger proportion than that in the bone union group (Table 4).

Several example cases are shown in Figs. 2, 3, and 4. Case 1 was distal femur fracture in a 74-year-old woman with TKA after a fall. Her injury was a simple transverse fracture that resulted in non-union. The alignment was reduced and LCP-DF was used as a bridging plate. It showed that the plate length was $196 \mathrm{~mm}$, fracture distance was $5 \mathrm{~mm}$, plate span ratio was $196 / 5=39.2$, bridge span length was $100 \mathrm{~mm}$, medial fracture distance was $4 \mathrm{~mm}$, and empty hole number was 4 . In this case, bone union was achieved by inserting screws near the fracture site via revision surgery, which increased 


\section{a}

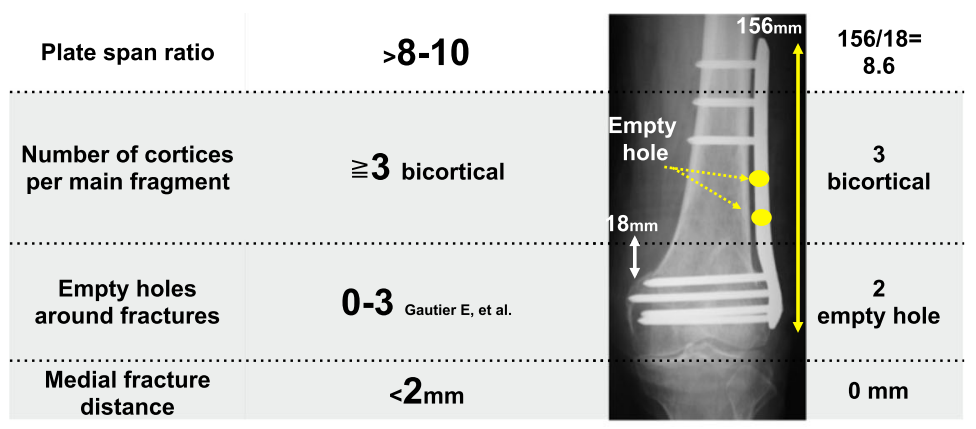

b

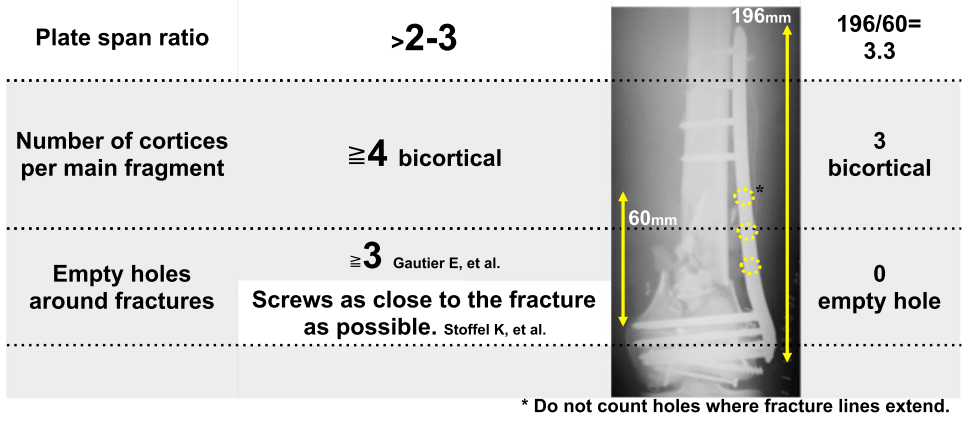

C

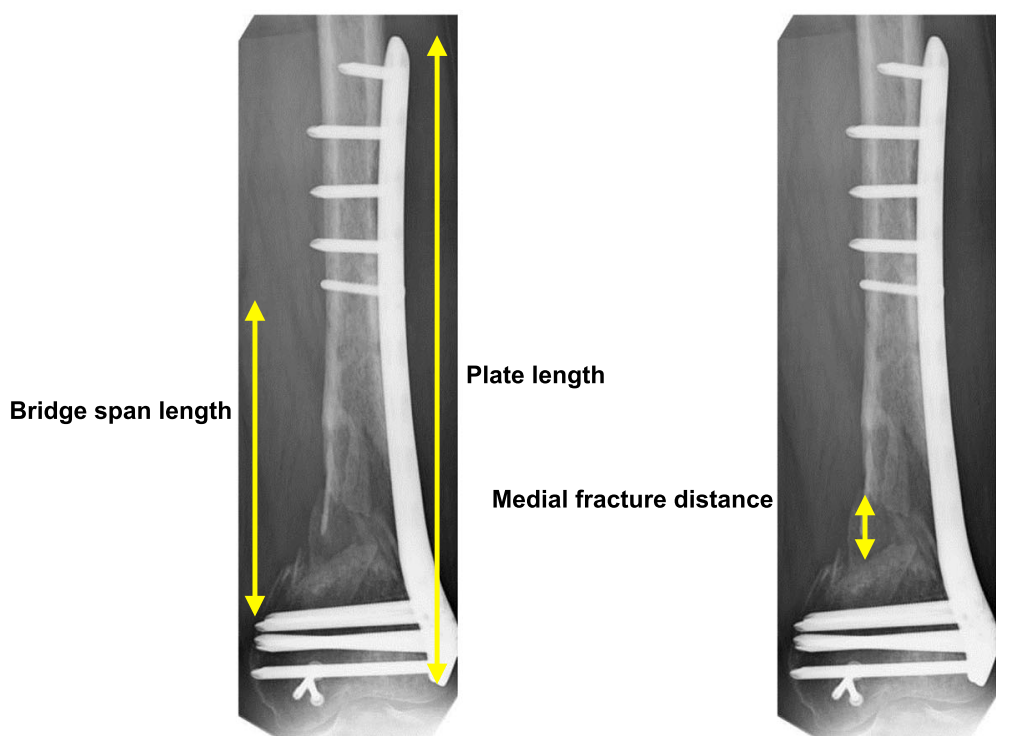

Fig. 1 Conclusive rules by Gautier et al. [14] and Stoffel et al. [15]. a Conclusive rules of simple fracture for 33A2 and 33C1. b Conclusive rules of comminuted fracture for $33 \mathrm{~A} 3,33 \mathrm{C} 2$, and $33 \mathrm{C} 3$. c The definition of the part measured this time

stability (Fig. 2). Case 2 was distal femur fracture with Gustilo IIIA in a 73-year-old man; he was run over by a shovel car. Callus formation was good, but resulted in non-union. It showed that plate length was $196 \mathrm{~mm}$, fracture distance was $39 \mathrm{~mm}$, plate span ratio was 196/ $39=5.02$, bridge span length was $65 \mathrm{~mm}$, medial fracture distance was $5 \mathrm{~mm}$, and empty hole number was 2 .
We believe that non-union was influenced by the instability of the fracture segment; therefore, another plate was added on the medial side (Fig. 3).

In case 3, it showed that plate length was $196 \mathrm{~mm}$, fracture distance was $65 \mathrm{~mm}$, plate span ratio was 196/65 = 3.01, bridge span length was $85 \mathrm{~mm}$, medial fracture distance was $0 \mathrm{~mm}$ (because of shortening fracture site), and 
Table 3 Characteristics of simple fractures (OTA 33A2, C1) $(n=$

\begin{tabular}{|c|c|c|c|}
\hline Characteristics & Non-union $(n=2)$ & Union $(n=24)$ & $p$ value \\
\hline Age, years & $76.2 \pm 11.6$ & $77.5 \pm 3.5$ & 0.89 \\
\hline Open fracture & 0 & 1 & $0.92^{*}$ \\
\hline MIPO & 1 & 22 & $0.22^{*}$ \\
\hline AO/OTA 33A2/C1 & $\mathrm{A} 2: 2$ & $A 2: 19 ; C 1: 5$ & \\
\hline \multicolumn{4}{|l|}{ Plate span ratio } \\
\hline$\geq 8-10$ & 0 & 3 & $0.77^{*}$ \\
\hline$<8-10$ & 2 & 21 & \\
\hline Number of empty holes & $2.5 \pm 1.5$ & $1.58 \pm 0.9$ & $0.17^{\dagger}$ \\
\hline 0 holes & 0 & 1 & \\
\hline 1 hole & 1 & 14 & \\
\hline$\geq 2$ holes & 1 & 9 & \\
\hline \multicolumn{4}{|l|}{ Medial fracture distance } \\
\hline$\geq 2 \mathrm{~mm}$ & 2 & 5 & $0.06^{*}$ \\
\hline$<2 \mathrm{~mm}$ & 0 & 19 & \\
\hline Bridge span length (mm) & $72.5 \pm 27.5$ & $72.2 \pm 24.9$ & $0.87^{\dagger}$ \\
\hline
\end{tabular}

Data are presented as mean \pm standard deviation or number

MIPO minimally invasive plate osteosynthesis, AO/OTA Arbeitsgemeinschaft für Osteosynthesefragen/Orthopedic Trauma Association

*Fisher's exact test

${ }^{\dagger}$ Mann-Whitney $U$ test empty hole number was 1 . Performing shortening and fixation of up to $5-10 \mathrm{~mm}$ was effective for achieving bone union in several comminuted fracture cases (Fig. 4).

\section{Discussion}

During surgery, it is sometimes difficult to properly determine screw position. Thus, the purpose of this study was to examine the appropriate screw position in relative fixation.

The guidelines reported by Gautier et al. suggested that a locking compression plate should be used as a bridging plate in order to achieve relative stability. Additionally, the researchers recommended that the plate length used in simple fractures should be 8-10 times longer than the fracture length, $0-3$ empty holes should be left in the surrounding space, the distance space should be $\leq 2 \mathrm{~mm}$, and $\geq 3$ screws should be inserted (bicortically) into the proximal and distal bone fragments [14]. For comminuted fractures, the guidelines recommend that the plate length should be at least 2-3 times longer than the fracture length and $\geq 3$ empty holes should be left in the surrounding fracture site. Additionally, according to Stoffel et al., the number of empty holes, including the fracture site, should be between one and four in simple fractures, and in comminuted fractures, the screws should be inserted as close to the fracture site as possible [15].

Although screw insertions near the fracture site increases fracture stability, in some cases, this may result in a lack of proper fracture micro-motion, leading to

Table 4 Characteristics of comminuted fractures (OTA 33A3/C2/C3) ( $n=45)$

\begin{tabular}{|c|c|c|c|}
\hline Characteristics & Non-union $(n=5)$ & Union $(n=40)$ & $\overline{p \text { value }}$ \\
\hline Age, years & $61.5 \pm 18.0$ & $68.4 \pm 19.9$ & 0.19 \\
\hline Open fracture & 4 & 14 & $0.14^{*}$ \\
\hline MIPO & 5 & 34 & $0.47^{*}$ \\
\hline AO/OTA 33A3/C2/C3 & $A 3,2 ; C 2,3$ & $A 3,15 ; C 2,10 ; C 3,15$ & \\
\hline \multicolumn{4}{|l|}{ Plate span ratio } \\
\hline$\geq 2-3$ & 5 & 36 & \multirow[t]{2}{*}{$0.61^{*}$} \\
\hline$<2-3$ & 0 & 4 & \\
\hline Number of empty holes & $2.0 \pm 0.5$ & $1.2 \pm 1.1$ & \multirow[t]{4}{*}{$0.07^{\dagger}$} \\
\hline 0 holes & 0 & 9 & \\
\hline 1 hole & 0 & 13 & \\
\hline$\geq 2$ holes & 5 & 18 & \\
\hline \multicolumn{4}{|l|}{ Medial fracture distance $\neq$} \\
\hline$\geq 5 \mathrm{~mm}$ & 5 & 0 & \multirow[t]{2}{*}{$0.00^{*}$} \\
\hline$<5 \mathrm{~mm}$ & 0 & 40 & \\
\hline Bridge span length (mm) & $81.2 \pm 30.7$ & $92.5 \pm 29.9$ & $0.54^{+}$ \\
\hline
\end{tabular}

Data are presented as mean \pm standard deviation or number

MIPO minimally invasive plate osteosynthesis, AO/OTA Arbeitsgemeinschaft für Osteosynthesefragen/Orthopedic Trauma Association

*Fisher's exact test

${ }^{\dagger}$ Mann-Whitney $U$ test

¥There was no significant difference at $2 \mathrm{~mm}$; however, there was a significant difference when the case was divided at $5 \mathrm{~mm}$ 


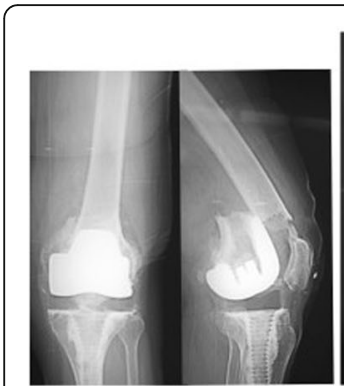

A

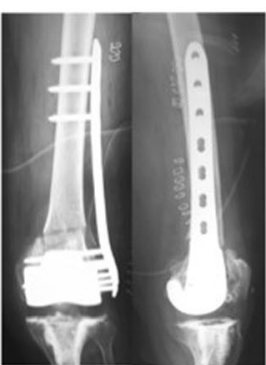

B

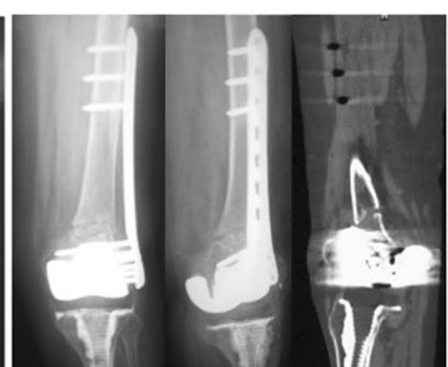

C

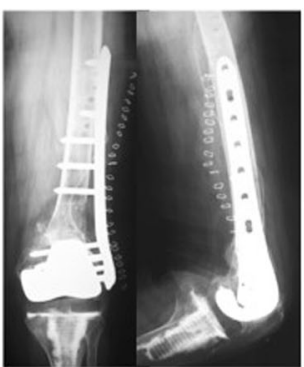

D

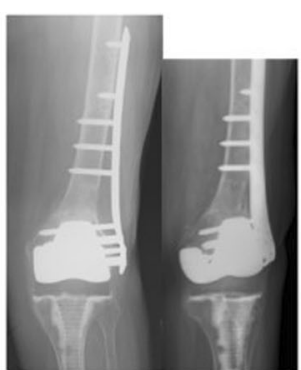

E

Fig. 2 a Radiograph in a 74-year-old woman with total knee arthroplasty. b Postoperative radiograph. c Radiograph and CT showed no callus at 6 months postoperatively. $\mathbf{d}$ Screws were inserted near the fracture during re-operation. e Radiograph 1 year after re-operation

poor callus formation [17]. The "far cortical locking technology" was demonstrated to increase fracture stability and flexibility; however, long-term results have not yet been obtained [18]. Megas et al. reported that fracture site instability prevents bone callus formation, even with good blood supply [19]. In most of our cases, nonunion likely resulted from fracture site instability after reduction internal fixation.

Henderson et al. reported no plate length differences between non-union and union groups, which was similar to our results [20]. Elkins reported favorable callus formation with a bridge span length of $\leq 80 \mathrm{~mm}$. Conversely, fracture instability was significantly higher with $>80 \mathrm{~mm}$ of bridge span length, which resulted in poor callus formation [21]. Lujan et al. reported that callus formation decreases as the bridge span length increases [22]. Bottland et al. reported that increasing fracture site flexibility promotes initial bone formation, but had no correlation with bridge span length [23]. Additionally, Henderson et al. reported no significant differences in bridge span lengths of 64.4 and $69.8 \mathrm{~mm}$ in two respective cases of non-union and union [20]. Our study also showed no significant differences between groups (Tables 2,3 , and 4 ).
Stoffel et al. advised to reduce the fracture site distance to $\leq 2 \mathrm{~mm}$ [15]. In our study, 7 of 26 simple fracture cases had a medial fracture distance of $\geq 2 \mathrm{~mm}$, and non-union was observed in 2 of these 7 (28.5\%) cases. Additionally, of the 45 cases with comminuted fractures, 13 cases had a medial fracture distance of $\geq 2 \mathrm{~mm}$, and non-union was observed in 4 of these 13 (30.7\%) cases. Bone union was observed in all cases with simple or comminuted fractures with respective medial fracture distances of $\leq 2 \mathrm{~mm}$ or $\leq 5$ $\mathrm{mm}$. Based on our findings, we concluded that bone fragment distance between fracture fragments is more important than bridge span length of the fracture site and the number of empty holes.

Reducing comminuted bone fragments is difficult when the inner portion of the fracture site also exhibits comminuted fracture. In such cases, shortening the fracture site to approximately $5-10 \mathrm{~mm}$ would be acceptable to decrease the distance between the proximal and distal bone fragments.

Regarding the number of empty holes, Stoffel et al. recommended opening 1-2 holes close to the fracture sites in simple fractures and inserting the screws as close as possible to the fracture sites in comminuted fractures [13]. In Henderson et al.'s study involving 70 patients,

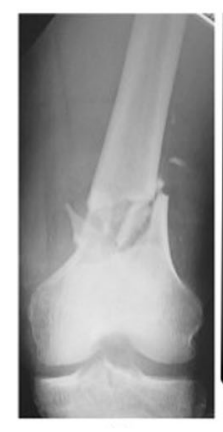

A

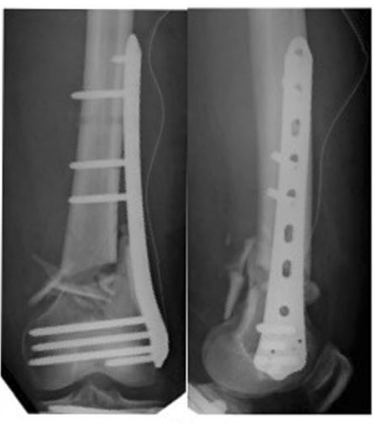

B

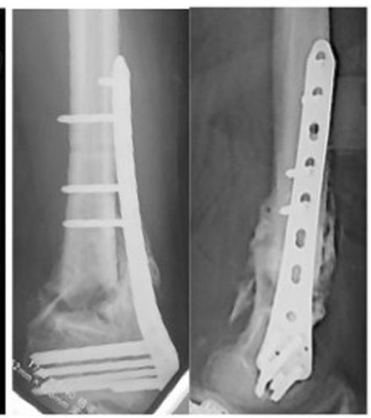

C

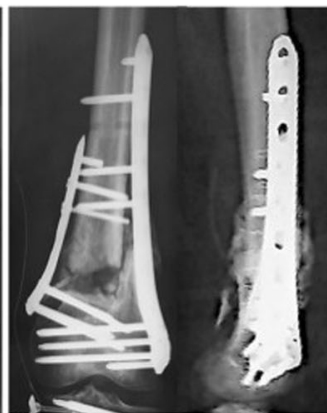

D

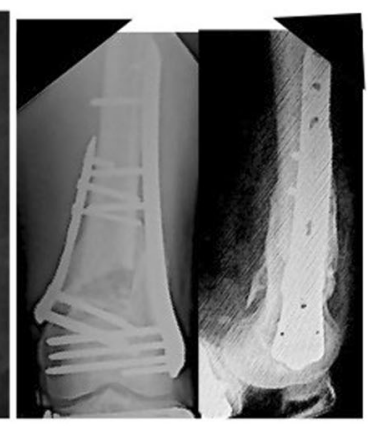

E

Fig. 3 a Radiograph with Gustilo type-IIIA in a 73-year-old man. b Postoperative radiograph. c Radiograph and CT showed non-union 8 months postoperatively. $\mathbf{d}$ Another plate was added during re-operation to shorten the fracture. e Radiograph 1 year after re-operation 


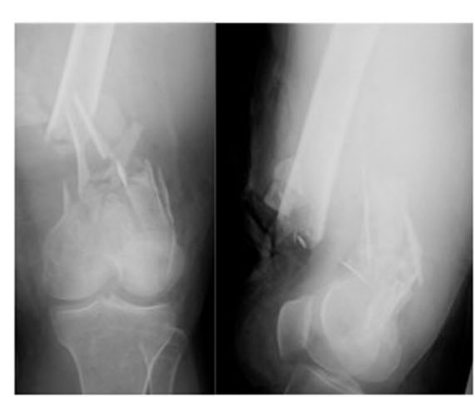

A

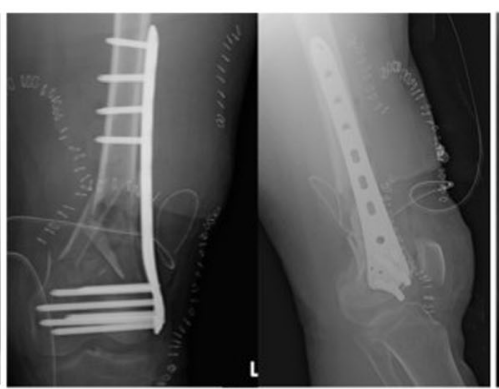

B
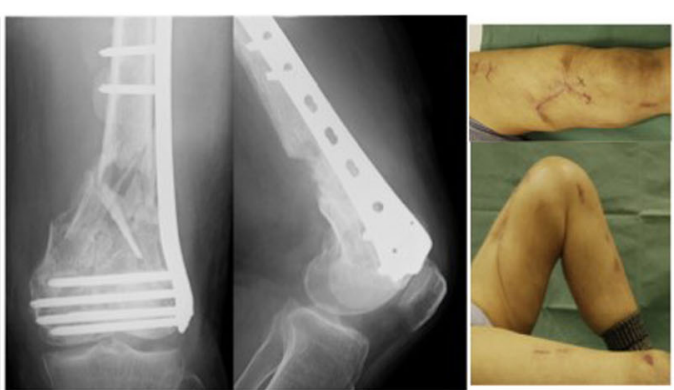

C

Fig. 4 a Radiograph with Gustilo type-IIIA in an 80-year-old woman. b Postoperative radiograph. c Radiograph and CT showed callus formation 2 months postoperatively; left knee range of motion was 0-140

the average number of empty holes proximal to the fracture site was 0.3 in the non-union group and 1.1 in the bone union group [20]. Additionally, Bottlang et al. observed a $19 \%$ bone union failure rate in a cohort of 70 patients and reported that there were significantly more empty holes proximal to the fracture site in the patients with non-union compared to those with successful bone union [23]. In our study, while there were no clear differences in the non-union rates as a result of the number of empty holes, non-union rate tended to increase as the number of empty holes increased in the proximal fragment in some cases. We believe that by decreasing the number of empty holes around the fracture site (i.e., inserting the screw near the fracture site), fracture site stability increased. Even with relative fixation, the more

Table 5 Healing complications of distal femoral fractures treated with locking plates

\begin{tabular}{|c|c|c|c|c|c|}
\hline Study & $\begin{array}{l}\text { Number } \\
\text { of } \\
\text { fractures }\end{array}$ & $\begin{array}{l}\text { Open } \\
\text { fractures, } \\
\%\end{array}$ & $\begin{array}{l}\text { Non- } \\
\text { unions, } \\
\%\end{array}$ & $\begin{array}{l}\text { Delayed } \\
\text { unions, } \\
\%\end{array}$ & $\begin{array}{l}\text { Average } \\
\text { time to } \\
\text { union, } \\
\text { weeks }\end{array}$ \\
\hline $\begin{array}{l}\text { Schandelmaier } \\
\text { et al. [25] }\end{array}$ & 54 & 19 & 2 & 6 & 13 \\
\hline $\begin{array}{l}\text { Fankhauser } \\
\text { et al. [26] }\end{array}$ & 30 & 47 & 0 & 3 & 12 \\
\hline $\begin{array}{l}\text { Schutz } \\
\text { et al. [27]. }\end{array}$ & 52 & 32 & 4 & 12 & \\
\hline $\begin{array}{l}\text { Vallier } \\
\text { et al. [28] }\end{array}$ & 46 & 54 & 9 & 15 & \\
\hline $\begin{array}{l}\text { Kayali } \\
\text { et al. [29] }\end{array}$ & 27 & 26 & 0 & & 15 \\
\hline $\begin{array}{l}\text { Henderson } \\
\text { et al. [22] }\end{array}$ & 12 & & 8 & 8 & \\
\hline $\begin{array}{l}\text { Ricci } \\
\text { et al. [3] }\end{array}$ & 305 & 29 & 14 & & \\
\hline $\begin{array}{l}\text { Rodriguez } \\
\text { et al. [23] }\end{array}$ & 283 & 18 & 14 & & \\
\hline $\begin{array}{l}\text { Harvin } \\
\text { et al. [30] }\end{array}$ & 99 & 29 & 34 & & \\
\hline
\end{tabular}

the empty hole, the higher the risk of a non-union, because bone union was achieved during salvage surgery in non-union cases through plate replacement with a long plate or inserting a screw near the fracture site.

Risk factors for non-union and delayed bone union in distal femoral fractures include the presence of open fracture(s), medial bone defects, and comminuted fracture(s) $[3,24]$. Compared with the proximal section of the femur or femoral trunk, poor blood supply in the distal femur has also been reported to contribute to a higher risk of non-union [25]. Reports published by various authors are listed in Table 5 [3, 23, 24, 26-31].

Study limitations included its retrospective design and the relatively small sample size. A senior medical doctor with $>15$ years of experience as an orthopedic surgeon operated on these cases; therefore, a certain surgery quality (reduction of fractures, treatment of soft tissues) was guaranteed. We analyzed several independent variables to determine how they impacted fracture healing; however, it is possible that other variables that were not considered may have contributed to the outcomes. Additionally, although we did not consider bone mineral densities and BMI, there is a possibility that they might have influenced bone union.

\section{Conclusions}

In distal femoral fractures, non-union sometimes may occur, despite improvements in implant and reduction techniques. Well-known risk factors include smoking, bone defects, and comminuted fractures, which were supported by this study's results. The bone fracture distance on the medial side of the distal femur was related to bone union rather than screw position. These results will be helpful in treating distal femoral fractures with plates.

Based on our findings, we concluded that bone fragment distance between fracture fragments is more important than bridge span length of the fracture site and the number of empty holes. The number of empty holes near the fracture site and the rate of bone healing were not clearly related. 


\section{Abbreviations}

AO/OTA: Arbeitsgemeinschaft für Osteosynthesefragen/Orthopedic Trauma Association; AP: Antero-posterior; LCP-DF: Locking compression plate for distal femur

\section{Acknowledgements}

Not applicable.

\section{Authors' contributions}

MK and TN designed the study. MK, TN, HN, TM, YY, YM, TU, SY, KD, KS, YS, and $\mathrm{TO}$ selected the appropriate patients and included them in this study. $\mathrm{MK}, \mathrm{TN}, \mathrm{HN}$, and TM performed the statistical analysis and interpreted the results. MK drafted the manuscript. All of the authors critically revised the manuscript. The final manuscript was approved by all authors.

\section{Funding}

Not applicable.

\section{Availability of data and materials}

The datasets used and analyzed during the current study are available from the corresponding author on reasonable request.

\section{Ethics approval and consent to participate}

The present study was approved by Okayama University Graduate School of Medicine, Dentistry, and Pharmaceutical Sciences and Okayama University Hospital (Ethics Committee No. 1712-035). The requirement for informed consent was waived due to this study's retrospective design.

\section{Consent for publication}

Not applicable.

\section{Competing interests}

The authors declare that they have no competing interests.

\section{Author details}

'Department of Orthopedic Surgery, Graduate School of Medicine, Dentistry and Pharmaceutical Sciences, Okayama University, 2-5-1, Shikata-cho, Kitaku Okayama City, Okayama Prefecture 700-8558, Japan. ${ }^{2}$ Department of Musculoskeletal Traumatology, Graduate School of Medicine, Dentistry and Pharmaceutical Sciences, Okayama University, 2-5-1 Shikata-cho, Okayama City, Okayama 700-8558, Japan. ${ }^{3}$ Department of Orthopedic Surgery, Kagawa Prefectural Central Hospital, 1-2-1 Asahi-Machi, Takamatsu City, Kagawa Prefecture 760-8557, Japan. ${ }^{4}$ Department of Orthopedic Surgery, Kagawa Rosai Hospital, Jotocho, Marugame, Kagawa Prefecture 763-8502, Japan. ${ }^{5}$ Department of Community and Emergency Medicine, Graduate School of Medicine, Dentistry and Pharmaceutical Sciences, Okayama University, 2-5-1, Shikata-cho, Kitaku, Okayama City, Okayama Prefecture 700-8558, Japan.

\section{Received: 25 June 2019 Accepted: 4 October 2019}

Published online: 26 November 2019

\section{References}

1. Kolmert L, Wulff K. Epidemiology and treatment of distal femoral fractures in adults. Acta Orthop Scand. 1982 Dec;53(6):957-62.

2. Court-Brown CM, Caesar B. Epidemiology of adult fractures: a review. Injury. 2006 Aug;37(8):691-7.

3. Ricci WM, Streubel PN, Morshed S, Collinge CA, Nork SE, Gardner MJ. Risk factors for failure of locked plate fixation of distal femur fractures: an analysis of 335 cases. J Orthop Trauma. 2014 Feb;28(2):83-9.

4. Gwathmey FW Jr, Jones-Quaidoo SM, Kahler D, Hurwitz S, Cui Q. Distal femoral fractures: current concepts. J Am Acad Orthop Surg. 2010 Oct; 18(10):597-607.

5. Ehlinger M, Ducrot G, Adam P, Bonnomet F. Distal femur fractures. Surgical techniques and a review of the literature. Orthop Traumatol Surg Res. 2013 May;99(3):353-60.

6. Smith WR, Ziran BH, Anglen JO, Stahel PF. Locking plates: tips and tricks. J Bone Joint Surg Am. 2007 Oct;89(10):2298-307.

7. Toolan BC, Koval KJ, Kummer FJ, Sanders R, Zuckerman JD. Vertical shear fractures of the medial malleolus: a biomechanical study of five internal fixation techniques. Foot Ankle Int. 1994 Sep;15(9):483-9.
8. Weight $\mathrm{M}$, Collinge $\mathrm{C}$. Early results of the less invasive stabilization system for mechanically unstable fractures of the distal femur (AO/OTA types A2, A3, C2, and C3). J Orthop Trauma. 2004 Sep;18(8):503-8.

9. Lee $\mathrm{CH}$, Shih KS, Hsu CC, Cho T. Simulation-based particle swarm optimization and mechanical validation of screw position and number for the fixation stability of a femoral locking compression plate. Med Eng Phys. 2014 Jan;36(1):57-64.

10. Hunt SB, Buckley RE. Locking plates: a current concepts review of technique and indications for use. Acta Chir Orthop Traumatol Cech. 2013;80(3):185-91.

11. Kellam JF, Meinberg EG, Agel J, Karam MD, Roberts CS. Introduction: fracture and dislocation classification compendium-2018: International Comprehensive Classification of Fractures and Dislocations Committee. J Orthop Trauma. 2018 Jan;32(Suppl 1):S1-10.

12. Heckman JD, Ryaby JP, McCabe J, Frey JJ, Kilcoyne RF. Acceleration of tibial fracture-healing by non-invasive, low-intensity pulsed ultrasound. J Bone Joint Surg Am. 1994 Jan;76(1):26-34.

13. Hoffmeier $\mathrm{KL}$, Hofmann GO, Mückley T. Choosing a proper working length can improve the lifespan of locked plates. A biomechanical study. Clin Biomech (Bristol, Avon). 2011;26(4):405-9.

14. Gautier E, Sommer C. Guidelines for the clinical application of the LCP. Injury. 2003 Nov;34(Suppl 2):B63-76.

15. Stoffel K, Dieter U, Stachowiak G, Gächter A, Kuster MS. Biomechanical testing of the LCP-how can stability in locked internal fixators be controlled? Injury. 2003 Nov;34(Suppl 2):B11-9.

16. Rekha YB, Reddy NB. A prospective study of treatment of distal femur fractures with locking condylar plate. Int J Res Orthop. 2017 Nov;3(6):1117-21.

17. Kanchanomai C, Muanjan P, Phiphobmongkol V. Stiffness and endurance of a locking compression plate fixed on fractured femur. J Appl Biomech. 2010 Feb;26(1):10-6.

18. Ries Z, Hansen K, Bottlang M, Madey S, Fitzpatrick D, Marsh JL. Healing results of periprosthetic distal femur fractures treated with far cortical locking technology: a preliminary retrospective study. lowa Orthop J. 2013;33:7-11.

19. Megas P. Classification of non-union. Injury. 2005 Nov;36(Suppl 4):S30-7.

20. Henderson CE, Kuhl LL, Fitzpatrick DC, Marsh JL. Locking plates for distal femur fractures: is there a problem with fracture healing? J Orthop Trauma. 2011 Feb;25(Suppl 1):S8-14.

21. Elkins J, Marsh JL, Lujan T, Peindl R, Kellam J, Anderson DD, Lack W. Motion predicts clinical callus formation: construct-specific finite element analysis of supracondylar femoral fractures. J Bone Joint Surg Am. 2016 Feb 17:98(4):276-84.

22. Lujan TJ, Henderson CE, Madey SM, Fitzpatrick DC, Marsh JL, Bottlang M. Locked plating of distal femur fractures leads to inconsistent and asymmetric callus formation. J Orthop Trauma. 2010 Mar;24(3):156-62.

23. Bottlang M, Doornink J, Lujan TJ, Fitzpatrick DC, Marsh JL, Augat P, von Rechenberg B, Lesser M, Madey SM. Effects of construct stiffness on healing of fractures stabilized with locking plates. J Bone Joint Surg Am. 2010 Dec; 92(Suppl 2):12-22.

24. Zlowodzki M, Bhandari M, Marek DJ, Cole PA, Kregor PJ. Operative treatment of acute distal femur fractures: systematic review of 2 comparative studies and 45 case series (1989 to 2005). J Orthop Trauma. 2006 May;20(5):366-71.

25. Santolini E, Goumenos SD, Giannoudi M, Sanguineti F, Stella M, Giannoudis PV. Femoral and tibial blood supply: a trigger for non-union? Injury. 2014 Nov;45(11):1665-73

26. Schandelmaier P, Partenheimer A, Koenemann B, Grün OA, Krettek C. Distal femoral fractures and LISS stabilization. Injury. 2001 Dec;32(Suppl 3): SC55-63.

27. Fankhauser F, Gruber G, Schippinger G, Boldin C, Hofer HP, Grechenig W. Szyszkowitz R. Minimal-invasive treatment of distal femoral fractures with the LISS (Less Invasive Stabilization System): a prospective study of 30 fractures with a follow up of 20 months. Acta Orthop Scand. 2004 Feb;75(1):56-60.

28. Schütz M, Müller M, Regazzoni P, Höntzsch D, Krettek C, Van der Werken C, Haas N. Use of the less invasive stabilization system (LISS) in patients with distal femoral (AO33) fractures: a prospective multicenter study. Arch Orthop Trauma Surg. 2005 Mar;125(2):102-8.

29. Vallier HA, Hennessey TA, Sontich JK, Patterson BM. Failure of LCP condylar plate fixation in the distal part of the femur. A report of six cases. J Bone Joint Surg Am. 2006 Apr;88(4):846-53. 
30. Kayali $\mathrm{C}$, Agus $\mathrm{H}$, Turgut $\mathrm{A}$. Successful results of minimally invasive surgery for comminuted supracondylar femoral fractures with LISS: comparative study of multiply injured and isolated femoral fractures. J Orthop Sci. 2007 Sep:12(5):458-65.

31. Harvin WH, Oladeji LO, Della Rocca GJ, Murtha YM, Volgas DA, Stannard JP, Crist BD. Working length and proximal screw constructs in plate osteosynthesis of distal femur fractures. Injury. 2017;48(11):2597-601.

\section{Publisher's Note}

Springer Nature remains neutral with regard to jurisdictional claims in published maps and institutional affiliations.

Ready to submit your research? Choose BMC and benefit from:

- fast, convenient online submission

- thorough peer review by experienced researchers in your field

- rapid publication on acceptance

- support for research data, including large and complex data types

- gold Open Access which fosters wider collaboration and increased citations

- maximum visibility for your research: over $100 \mathrm{M}$ website views per year

At $B M C$, research is always in progress.

Learn more biomedcentral.com/submissions 